Janeth Milena Vargas Patiño*, Carlos Mario Rodríguez Rodríguez**

\title{
Territorios del color: análisis del imaginario del color de Ráquira ${ }^{1}$
}

\author{
Territories of color: analysis of Raquira's imaginary of \\ color
}

Cómo citar:

Rodríguez, C. M. \& Vargas J. (2018). Territorios del color: análisis del imaginario del color de Ráquira. Designia 5(2), 101-119.

${ }^{1}$ Este artículo se deriva del proyecto Territorios de color en Boyacá, desarrollado por el semillero de investigación Gama del programa de Diseño Gráfico de la Universidad de Boyacá.

* Estudiante del programa de Diseño Gráfico de la Universidad de Boyacá e integrante del semillero de investigación Gama. janvargas@uniboyaca.edu.co. orcid.org/0000-0003-2533-6136

**Diseñador Gráfico. Magíster en entornos virtuales de aprendizaje. Docente de la Universidad de Boyacá y coordinador del semillero de investigación Gama. carrodriguez@uniboyaca.edu.co. orcid.org/0000-0002-5670-7393

Palabras clave:

imaginario, color, territorio, percepción, identidad.

Key words:

imaginary, color, territory, perception, identity.

Recibido: 31/07/2018 Aceptado: 03/10/2018

\section{Resumen:}

Este artículo presenta los resultados de una fase del proyecto investigativo Territorios del color, desarrollada en Ráquira (Boyacá). Se estudió el color imaginado por los pobladores a partir de las asociaciones cromáticas definidas por estos en la percepción del entorno y en la experiencia de habitar el lugar. Se identificaron así imaginarios urbanos relacionados con cargas afectivas, emocionales y sensoriales. Con estos hallazgos se elaboró una síntesis gráfica que plantea una caracterización del municipio basada en las tonalidades referidas. La propuesta metodológica de enfoque cualitativo 
empleó como instrumentos para la recolección de datos una encuesta aplicada a la población y un taller con estudiantes de secundaria de un colegio local. Conjuntamente con esta información primaria se examinó literatura especializada. El trabajo evidenció que el análisis del color desde la perspectiva del habitante permite leer la cultura del lugar y promueve un diálogo con la comunidad. De este modo, a su vez, es posible caracterizar elementos de identidad cultural e impulsar su reconocimiento y apropiación.

\section{Abstract:}

This paper describes the results from a stage of the Territories of color research project, which was conducted in Ráquira (Boyacá). Color imagined by the town's inhabitants was studied on the basis of the chromatic relations they make when perceiving their environment and living in the place. Urban imaginaries related to affective, emotional and sensory loads were thus recognized. These findings allowed to create a graphic summary proposing the town's characterization based on the tones identified. The project followed a qualitative methodological approach that employed a survey, applied to the population, along with a workshop targeting a local school's students for the data collection. In addition to this primary information, specialized literature was also examined. It was evidenced how the analysis of color from the dweller's perspective enables a reading of the place's culture and promotes a dialogue with the community. In this way, it is possible to characterize cultural identity elements, fostering their recognition and appropriation. 
INTRODUCCIÓN
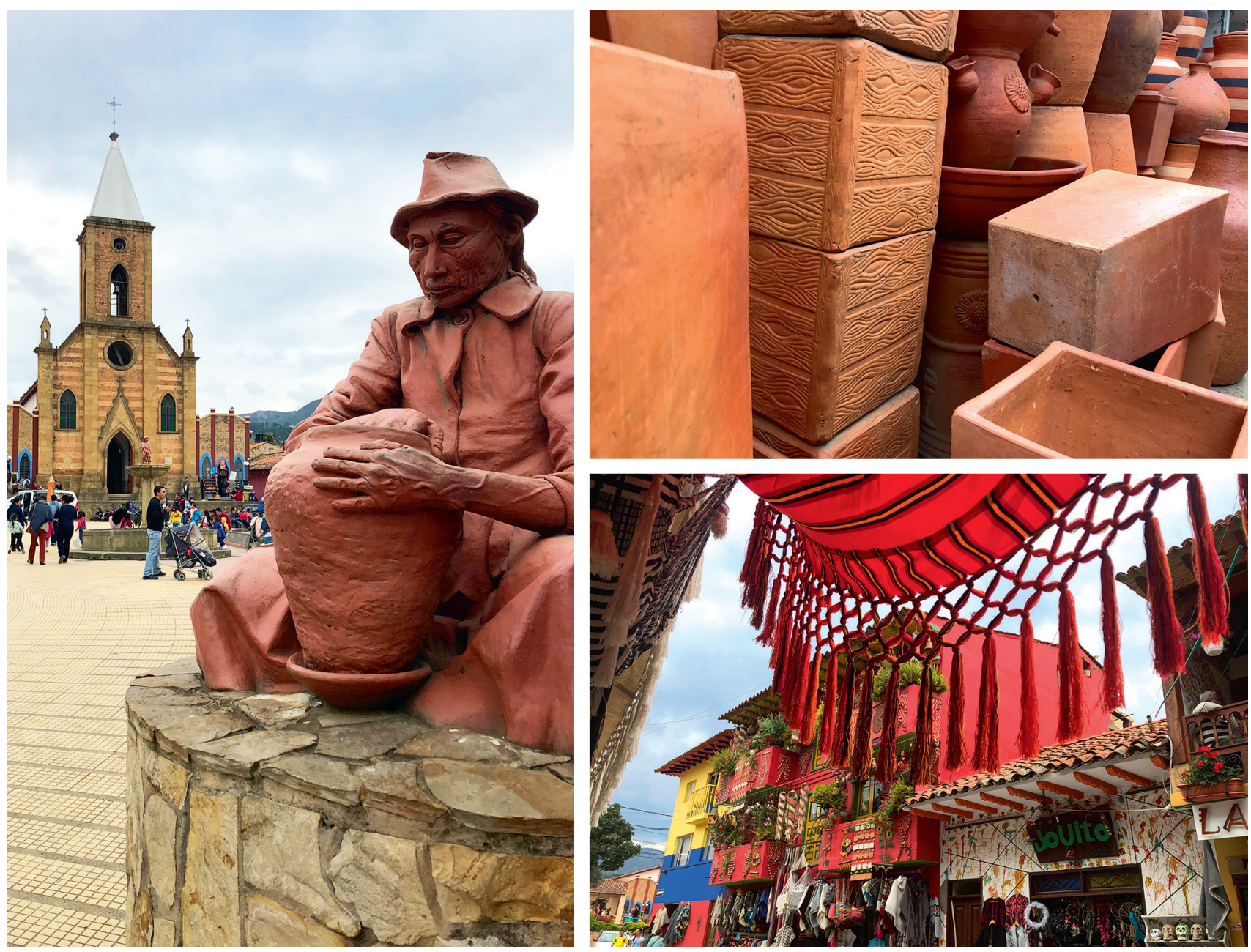

"ป

103

Figura 1. Municipio de Ráquira.

Fuente: fotografías de los autores. 
Ráquira es una utopía del color. El municipio, uno de los principales atractivos turísticos del departamento de Boyacá, ha sido considerado como capital artesanal de Colombia y es reconocido en el exterior por sus productos, elaborados principalmente en arcilla (Gobernación de Boyacá, 2012). Sin embargo, Ráquira no fue siempre el municipio colorido de la actualidad, esta imagen fue adoptada a comienzos de la década del 90, cuando el arquitecto Antonio Sanabria tuvo la idea de devolver al lugar la imagen que posiblemente tuvo en la época de la colonia. Una noticia del diario El Tiempo, retrata el suceso de la siguiente manera:

La pintada Ráquira era un pueblo común y corriente (...) Sus fachadas alternaban los colores blanco y rojo o blanco y azul, de acuerdo con los decretos de los alcaldes de turno, liberales y conservadores, desde hace más de cien años.

Los más rebeldes le ponían si acaso un tono café a sus fachadas, y los demás dejaban que el curso del tiempo decidiera por ellos.

Daniel Antonio Sanabria, el alma de esa revolución, es un arquitecto tunjano que ha vivido más de 14 años fuera del país (...) Un día descubrió que debajo de tanto barniz lúgubre ordenado por las administraciones liberales y conservadoras, había capas de pintura preparada por los indígenas desde la época de la Colonia. (amarillo, azul y rojo) que eran los que manejaban los aborígenes.

Cada vez que se arrimaba a una edificación de esas viejas, raspaba con una moneda, con mucho disimulo, y siempre hallaba sorpresas.

Hace cuatro meses cuando vino a pasar vacaciones a su tierra se le ocurrió la idea de pintar todo un pueblo con los colores originales de la Colonia. Y Ráquira era una buena posibilidad. Apenas 152 casas no parecía un reto tan duro. (Peña, 1994).

Este ha sido el punto de partida y el suceso de interés que ha llevado a considerar a Ráquira, como un objeto de estudio pertinente para ser incluido en el desarrollo del proyecto Territorios de color en Boyacá, cuyo objetivo es reconocer la identidad del departamento mediante el análisis cromático del paisaje, las áreas urbanas y las manifestaciones culturales de sus municipios. 
Ráquira fue abordada desde dos perspectivas: los colores físicos, observables en las fachadas y el mobiliario urbano; y de otro lado, el color imaginado, correspondiente a las formas como los habitantes perciben y se relacionan con esa gama cromática. En este artículo se tratan los resultados de la última parte y se espera próximamente realizar un análisis comparativo de ambas.

Para definir los colores que hacen parte de la identidad de Ráquira se implementó un estudio fenomenológico de carácter descriptivo y enfoque cualitativo, cuyos instrumentos de recolección de datos fueron la encuesta y el taller. La investigación se dividió en cinco fases. Inicialmente, la consulta de referentes proporcionó la relevante fundamentación teórica e indicó el curso metodológico. A continuación, se aplicaron los instrumentos a los pobladores. La información obtenida se registró en fichas tipológicas que facilitaron el análisis. Los resultados, clasificados y desglosados infográficamente, detallaron lo relacionado con las cargas emocionales y afectivas asociadas al color.

Por último, se elaboraron piezas gráficas que sintetizan los datos cualitativos, ofrecen un análisis del color desde imaginarios urbanos de Ráquira y evidencian las particularidades cromáticas allí presentes. Este examen permitió reconocer problemáticas manifestadas en el territorio, como también realidades ligadas a tradiciones representativas del lugar.

\section{REFERENTES CONCEPTUALES}

Es necesario considerar referentes metodológicos de proyectos orientados al estudio del color al igual que el estado del arte en materia de teoría y conceptos sobre color urbano.

En cuanto a los significados y símbolos de un lugar y cómo afectan estos la relación de las personas con su entorno, un estudio de la zona centro de Tijuana (México) (Zúñiga, 2014) exploró la relación entre paisaje e imaginario a partir de las apropiaciones espaciales de sus habitantes. El repertorio consolidado permitió especificar que "el sujeto se apropia y relaciona con el territorio a través de representaciones, significados y 
símbolos; los paisajes poseen una excepcionalidad o carácter único que se construye tanto de elementos morfológicos como simbólicos" (p. 4). La coexistencia de estas dimensiones en un medio urbano, las cuales dependen de la experiencia espacial y el nivel de apropiación de quien lo habita, fue considerada para el estudio comparativo entre la dimensión física del color y su dimensión simbólica o imaginada en Ráquira.

En relación con las implicaciones del color físico, el proyecto global de Phillipe Lenclos (1999) elaboró una caracterización cromática de varias ciudades del mundo que le llevó a exponer la teoría de la Geografía del color. Según esta, los distintos tonos presentes en un lugar son parte del valor patrimonial intangible del territorio.

Como parte de las aproximaciones al color urbano realizadas en Chile por Laura Rodríguez (2011), para el diseño del proyecto de vivienda Unidos por un sueño, se aplicó una metodología en que la selección cromática se efectuó muy de la mano con la población. En este trabajo interdisciplinar entre estudiantes de arquitectura y antropología se utilizaron croquis, fotografías y entrevistas con el fin de definir los colores soñados por la comunidad para su nuevo barrio. A partir de esta experiencia se consideró la pertinencia de la participación ciudadana en el estudio de Ráquira y se entendió que el color está ligado a la identidad de los habitantes al ser un conector entre estos y el espacio construido, un enlace con potencial para unir la imagen fragmentada de las urbes.

Para la comprensión del color de las ciudades y el análisis de percepciones también se retomó la metodología propuesta por Silva (2014) al estudiar imaginarios urbanos.

Igualmente, se prosiguió la orientación metodológica que para identificar percepciones cromáticas en dichos imaginarios ha sido aplicada en trabajos previos por Rodríguez, quien conceptualiza así cuanto implica examinar la diversidad de expresiones urbanas:

\footnotetext{
La ciudad no solo es un hecho físico tangible, definir ciudad implica ir más allá de lo que se ve, requiere sumergirse en la percepción de sus habitantes, entender cómo es vista, aprender a quererla, aceptar sus irregularidades y desfases, caminarla y encontrar cosas nuevas, saber su esencia, su olor, su sabor, su color (2013, p. 11).
} 
Acerca del análisis del color imaginado afirma Rodríguez: "contempla la metodología de estudio del imaginario social, fundamentada en herramientas de investigación como el diario de campo, la observación, las entrevistas y la aplicación de encuestas a la ciudadanía" (2014a, p. 33). A su vez, sobre el carácter del color en la ciudad señala:

\begin{abstract}
es un elemento condicionante de la percepción visual del ambiente, tiene incidencia en la comunicación, representa la vitalidad del lugar y hace parte de todos los componentes visuales del entorno, tanto naturales como aquellos creados por el hombre. En la ciudad el color del entorno hace parte de la producción de imaginarios urbanos y construcciones mentales de los habitantes así como de las dinámicas culturales ocurridas en la interacción del ciudadano con los lugares de la ciudad (Rodríguez, 2014b, p. 62).
\end{abstract}

En lo concerniente al papel de quien investiga desde el campo del diseño, como se propone en el caso de Ráquira, puntualiza Rodríguez (2016) que se trata de un "agente traductor de procesos semióticos, que ya sea desde la escritura y descripción de propuestas gráficas o visuales, hace posible la materialización de conceptos abstractos como lo son las percepciones sensoriales y los imaginarios" (p. 89).

\title{
FUNDAMENTOS METODOLÓGICOS
}

La propuesta metodológica fue de tipo fenomenológico pues se ocupó de la percepción de los habitantes del municipio. Si bien se emplearon instrumentos cuantitativos se tuvo como fin realizar una lectura y una caracterización de la identidad de dicho lugar, por lo tanto, la investigación fue de corte descriptivo y carácter cualitativo.

La encuesta masiva, aplicada a la comunidad en general, tuvo esta pregunta abierta: ¿De qué color es Ráquira? Por su parte, el taller se efectuó con estudiantes de los grados décimo y once del colegio San Antonio, situado en el municipio. Este ejercicio incluyó actividades de dibujo y escritura en que los participantes relacionaron sus emociones con determinados lugares, lo cual se tradujo en cargas afectivas asociadas al color. Los datos obtenidos con estos instrumentos se analizaron por medio de fichas tipológicas para calcular lo "cualificable" del estudio. Posteriormente, se dio la construcción de sentido. 

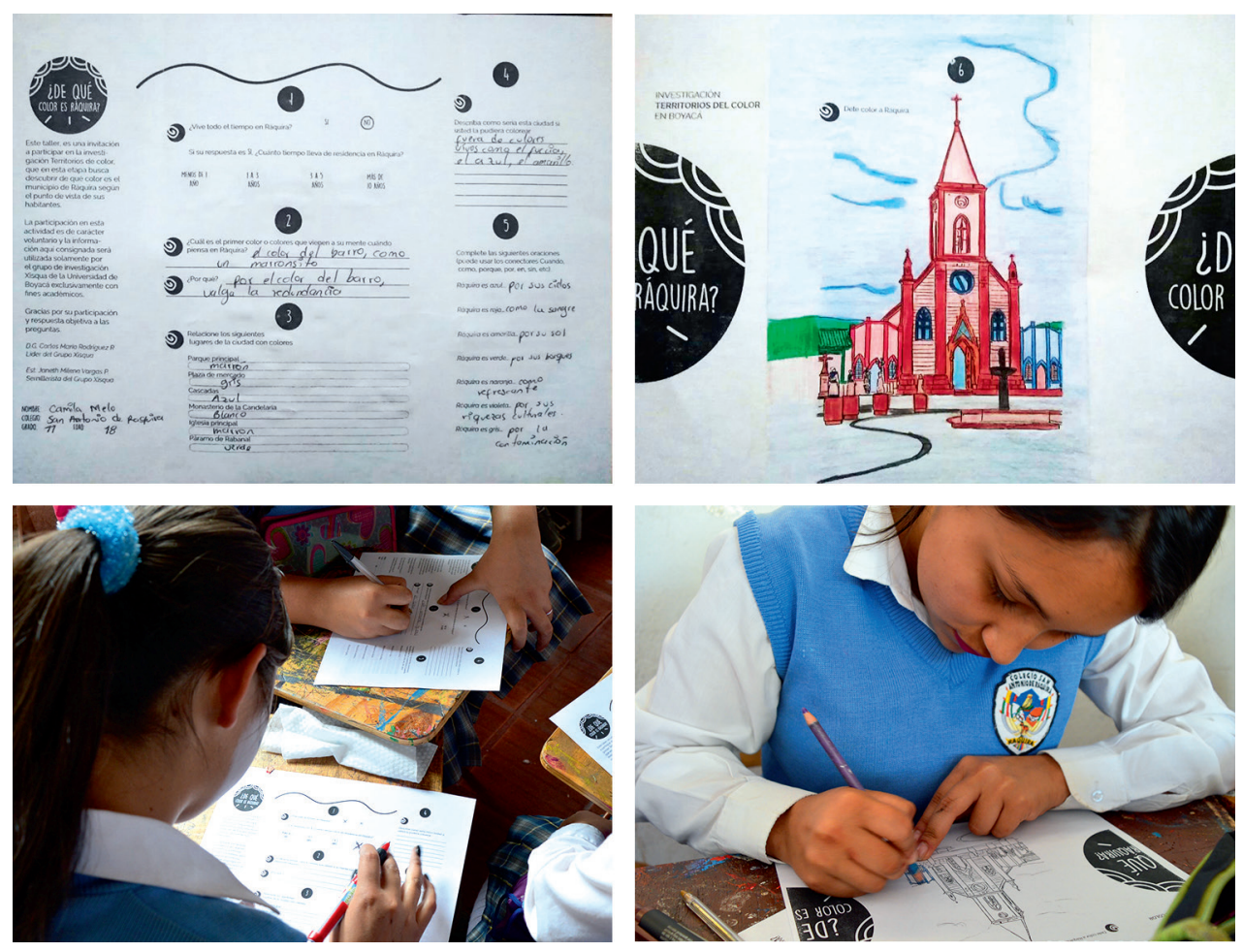

Figura 2. Aplicación de instrumentos.

Fuente: autores.

\section{RESULTADOS}

La información se estructuró desde lo general hasta lo específico de manera que se llegó a resultados que expresan los datos cuantitativos de forma cualitativa.

La encuesta evidenció que gran parte de la población percibe un municipio multicolor, en especial por los tonos presentes en las fachadas de la mayoría de casas. También se destacan el verde, relacionado con la naturaleza; el amarillo y el naranja-terracota, por la arcilla y la artesanía fabricada con esta. Igualmente, fueron considerados para describir la imagen del lugar: el rojo, vinculado con los minerales aplicados al material; el azul asociado a la tranquilidad, el cielo y el río; el gris y el negro, los cuales hablan de la contaminación y el problema ambiental causado por los hornos empleados en la alfarería. 


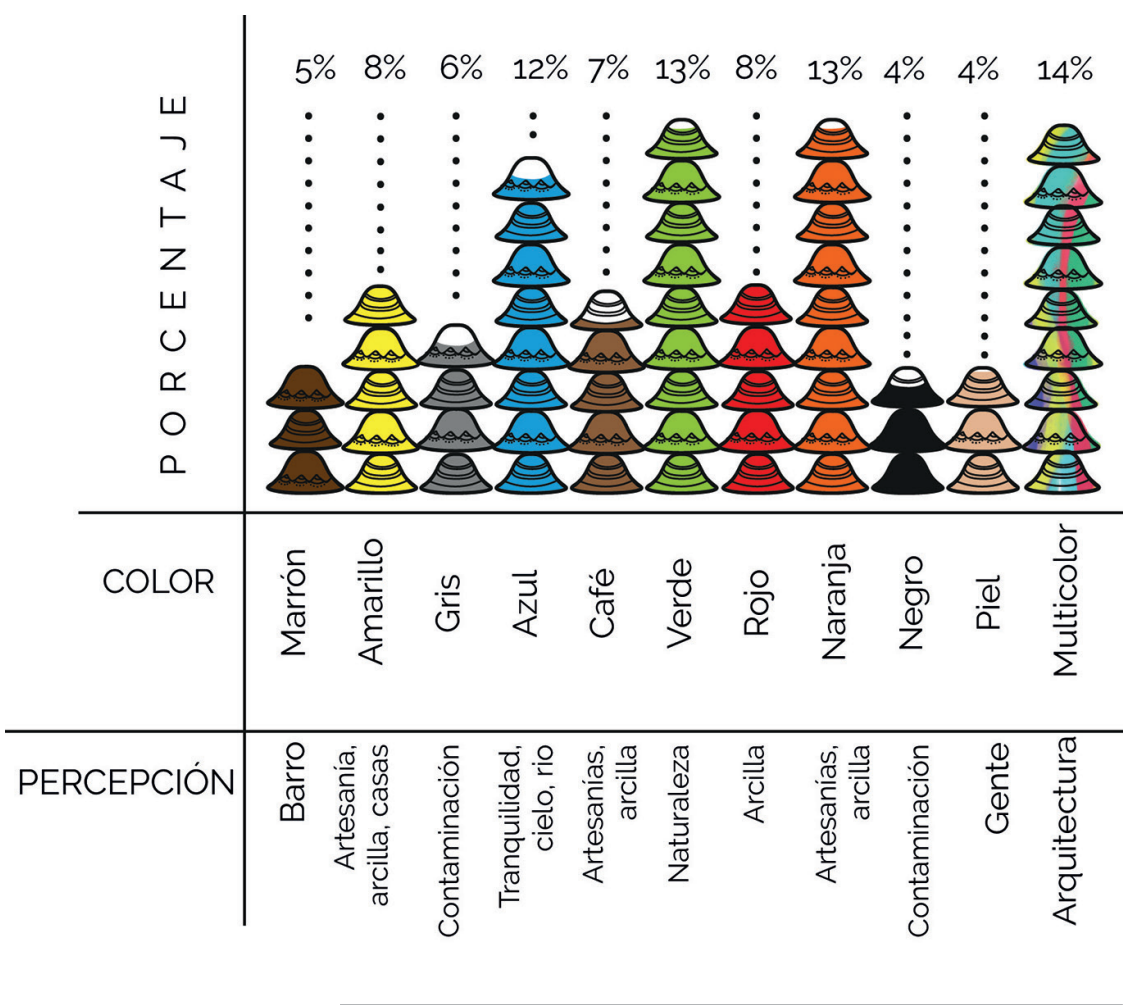

Figura 3. Resultados de la encuesta.

Fuente: autores.

Los resultados de los talleres con los estudiantes fueron cuantificados por porcentajes y proporcionaron especificaciones de las percepciones. Así, respecto a la percepción del lugar, las mujeres imaginan un municipio verde, amarillo, azul, naranja y café, en orden de mayor a menor incidencia. Entre los varones predomina el verde, seguido del naranja, el azul y el amarillo. Ambos sexos reconocen el verde como el color más representativo y coinciden en el naranja, el azul y el amarillo. 
La percepción cromática de Ráquira difiere entre quienes han residido allí por más de diez años, aquellos que lo han hecho de tres a cinco y los visitantes. Entre los primeros sobresalen el naranja, representado en la arcilla, el verde, por la naturaleza, y el azul, por la tranquilidad. Los segundos destacan el marrón, el amarillo y el azul, relacionados con la arcilla, la artesanía y las cascadas, respectivamente. Por su parte, para los visitantes es un lugar verde, en razón de su naturaleza y paisaje.

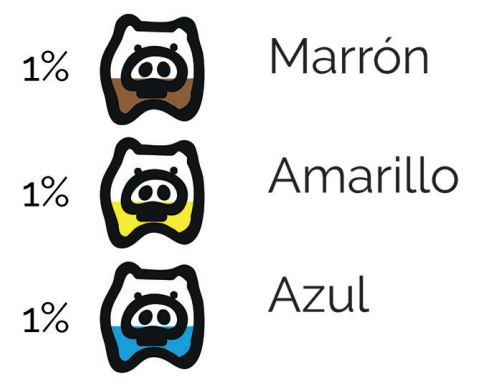

Figura 4. Percepción del color del municipio entre los residentes de tres a cinco años.

Fuente: autores.

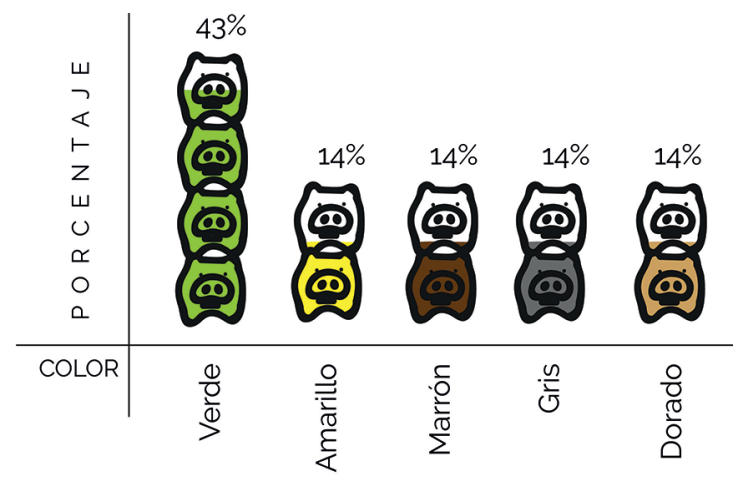

Figura 5. Percepción del color del municipio entre los visitantes . 
Con el fin de particularizar tonalidades específicas para los sitios más representativos, como son el parque principal, la iglesia, el monasterio de La Candelaria, la plaza de mercado, el páramo de Rabanal y las cascadas La Chorrera, se preguntó a los habitantes por el color con que identifican a estos. Los resultados se presentan en la figura 6.

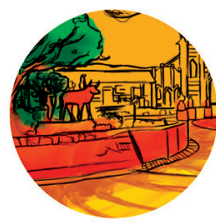

PARQUE PRINCIPAL NARANJA

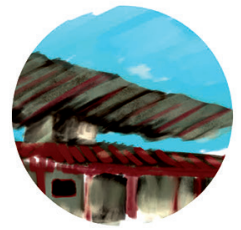

PLAZA DE MERCADO GRIS

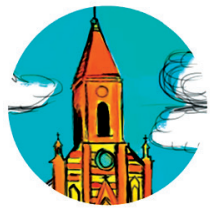

IGLESIA DE RÁQUIRA

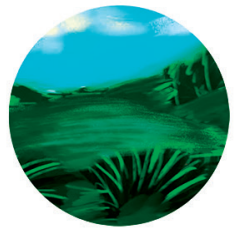

PÁRAMO DE

NARANJA Y CAFÉ RABANAL

VERDE

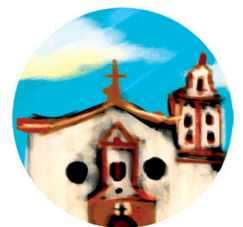

MONASTERIO DE LA CANDELARIA 
Según los resultados del taller sobre este particular, para el parque predominan los tonos naranja, debido a las construcciones en ladrillo y las estatuas de barro allí exhibidas. La iglesia se relaciona con naranja y marrón, pues tales son los colores de su material principal (ladrillo) que está a la vista. En el monasterio el color físico también concuerda con el imaginado al prevalecer el blanco. Aunque la plaza de mercado no es gris, un gran número de personas la vinculan a este color opaco, debido a su ambiente interior y a las sensaciones respecto al espacio. El páramo es percibido con distintas gamas de verde mientras que las cascadas se enlazan con el azul, representación del agua y su frescura.

Asimismo, se encontraron marcaciones que expresan distintas formas de caracterizar a Ráquira de acuerdo con cada color, tal como se precisa en las figuras 7 a 12.

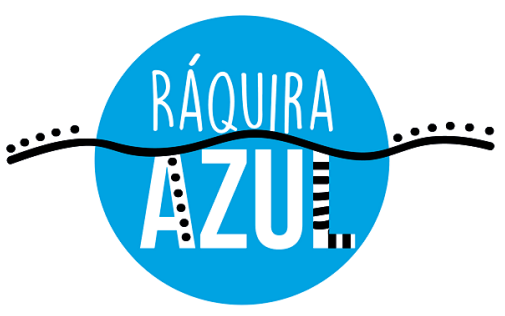

Por su cielo y el agua de ríos, cascadas, pozos y lagunas. 


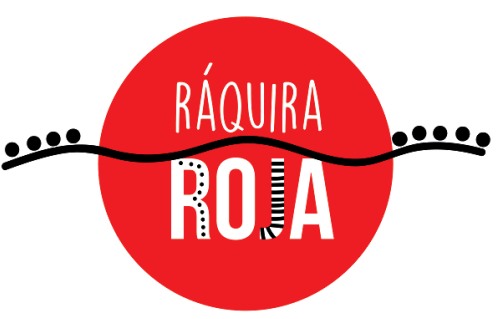

Por su arcilla y los minerales de esta, como también por las fachadas $\mathrm{y}$ tejados de las casas.

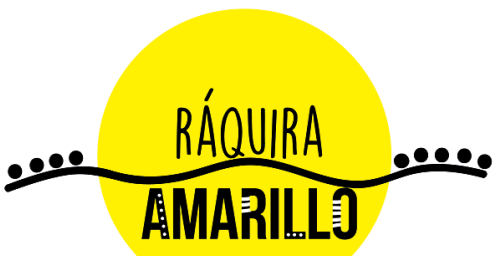

Por su artesanía, sus productos de barro y lugares representativos; por el sol, el calor, el parque, las casas y el colegio.

Figura 8. Rojo.

Figura 9. Amarillo.

Fuente: autores.

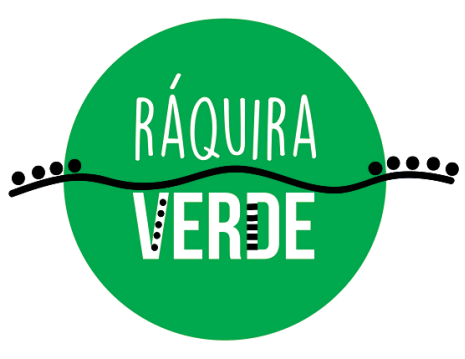

Por su naturaleza y vegetación, por sus paisajes, montañas y páramos.

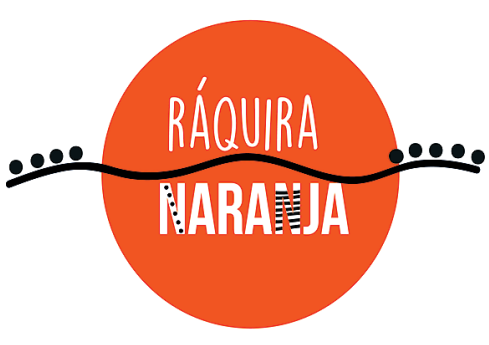

Por su artesanía en barro y arcilla y sus materas. Por su arquitectura, su iglesia y sus fachadas. 


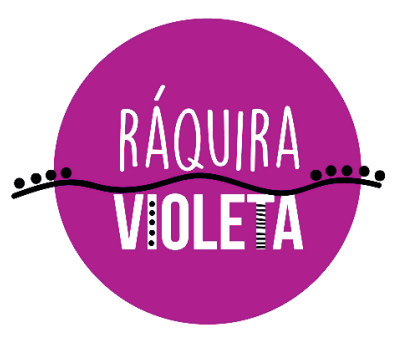

Por los detalles de las fachadas, las flores y las manifestaciones culturales.

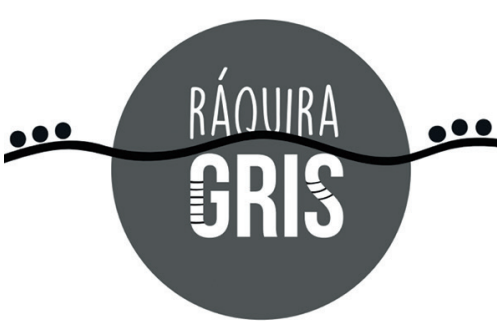

Por los días lluviosos y la contaminación causada por los hornos que desprenden humo.

Figura 12. Violeta.

Figura 13. Gris.

Fuente: autores.

En un ejercicio de dibujo realizado como parte del taller se siguió la propuesta de Silva (2004) para definir distintas síntesis del color y las relaciones de estas con el entorno. Los estudiantes propusieron los tonos que imaginan para Ráquira y expresaron a manera de ecuaciones asociaciones con el lugar. Se obtuvieron los siguientes resultados:

Azul + Amarillo $=$ Cascadas + Sol . En este caso, la gama de los azules predomina sobre la de los amarillos. A su vez, para expresar de manera simplificada el azul, representado en el cielo, se planteó la fórmula Azul+ Gris = Cielo+ Contaminación. El humo producido por los hornos en que se cocina la arcilla es entendido como un elemento negativo.

Las tonalidades violeta expresan un nexo directo con las flores: Violeta + Verde $=$ Flores + Naturaleza. Se registraron más de estas tonalidades en sus distintas gradaciones, de frías a cálidas, que de verde. El término "naturaleza" sirvió para abarcar árboles y páramo. 
El violeta se vinculó, adicionalmente, con la pintura empleada en los detalles de las artesanías y las fachadas de las casas. Por tal motivo, puede incorporarse en la fórmula Violeta + Naranja = Arcilla + Artesanía, la cual indica el contraste entre el color natural de la arcilla y las pinturas usadas en la decoración de los productos artesanales.

En la gama de amarillos, además del sol, también se reconoció la arcilla: Amarillo + Rojo $=$ Arcilla + Minerales. El rojo se consideró como los minerales presentes en el material.

Finalmente, como fórmula general se propuso: Café + Amarillo + Naranja + Rojo $=$ Arcilla.

Estas fórmulas del color en el municipio según la percepción de sus habitantes se plasman en una serie de cinco carteles tituladados Ráquira es... Se planteó este producto al considerar que el cartel, como forma de expresión gráfica, permite comunicar los resultados obtenidos y ayuda a comprender los imaginarios en los cuales se enfocó el proyecto investigativo. Las piezas se expusieron en el colegio San Antonio, donde se realizaron los talleres. De esta forma, se cierra el diálogo con la población mediante una dinámica participativa en torno a los aspectos positivos y negativos ligados al color. 
El cartel Ráquira es... Arcilla, deja ver cuatro colores (amarillo, naranja, rojo y cafe) que representan el material ancestral, culturalmente aceptado como fuente de trabajo de los artesanos. Por su parte, Ráquira es... Naranja, relaciona este tono con la alfarería, principal actividad económica y de ingresos. Otra de las representaciones se refiere a la característica multicolor, atribuible a la artesanía y la arquitectura, y una más reconoce el violeta como cualidad cromática debido a la flora, en particular las flores de la región.

Con el cartel dedicado al gris se buscó evidenciar la contaminación generada por la producción alfarera, al igual que el contraste existente entre la imagen idealizada de los visitantes, quienes perciben un lugar multicolor, y aquella de gran parte de los pobladores, cuyas mentes imaginan este tono a causa de la mencionada problemática ambiental.
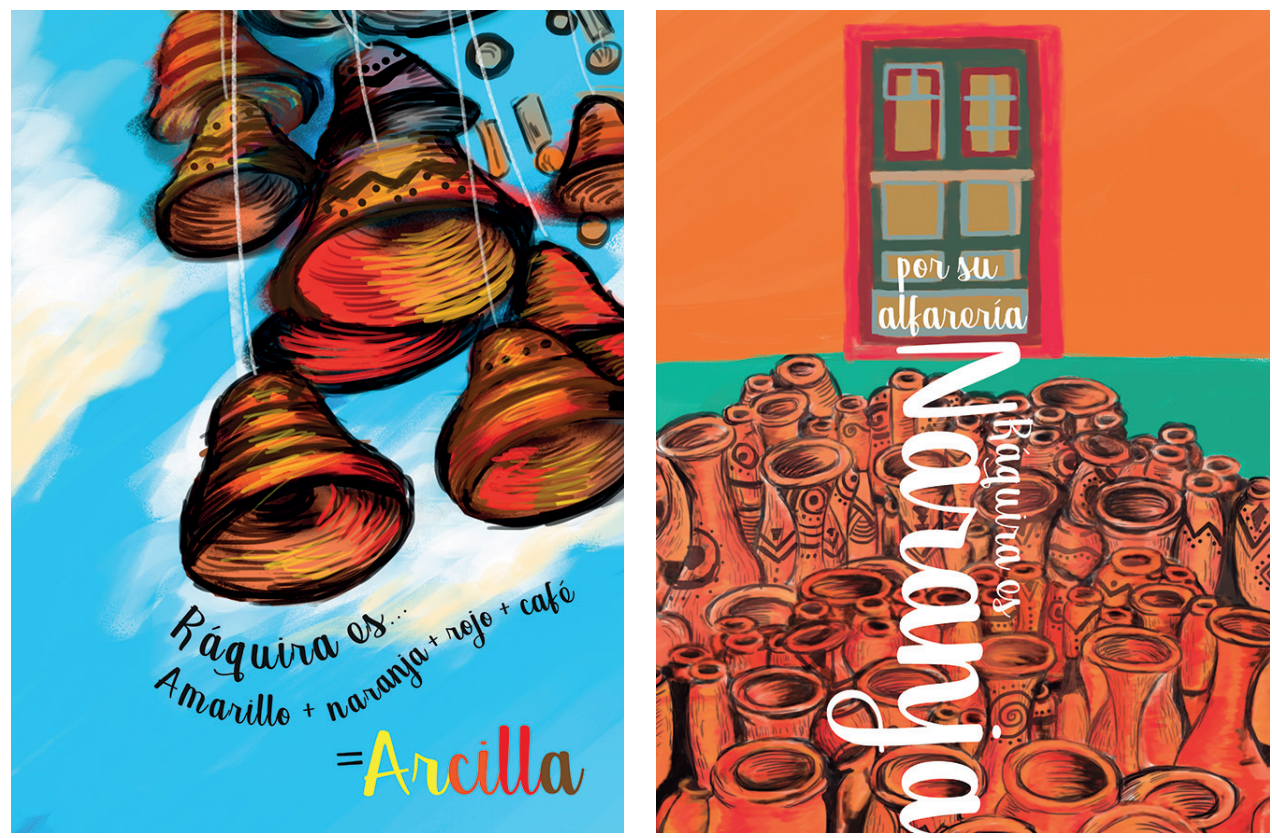

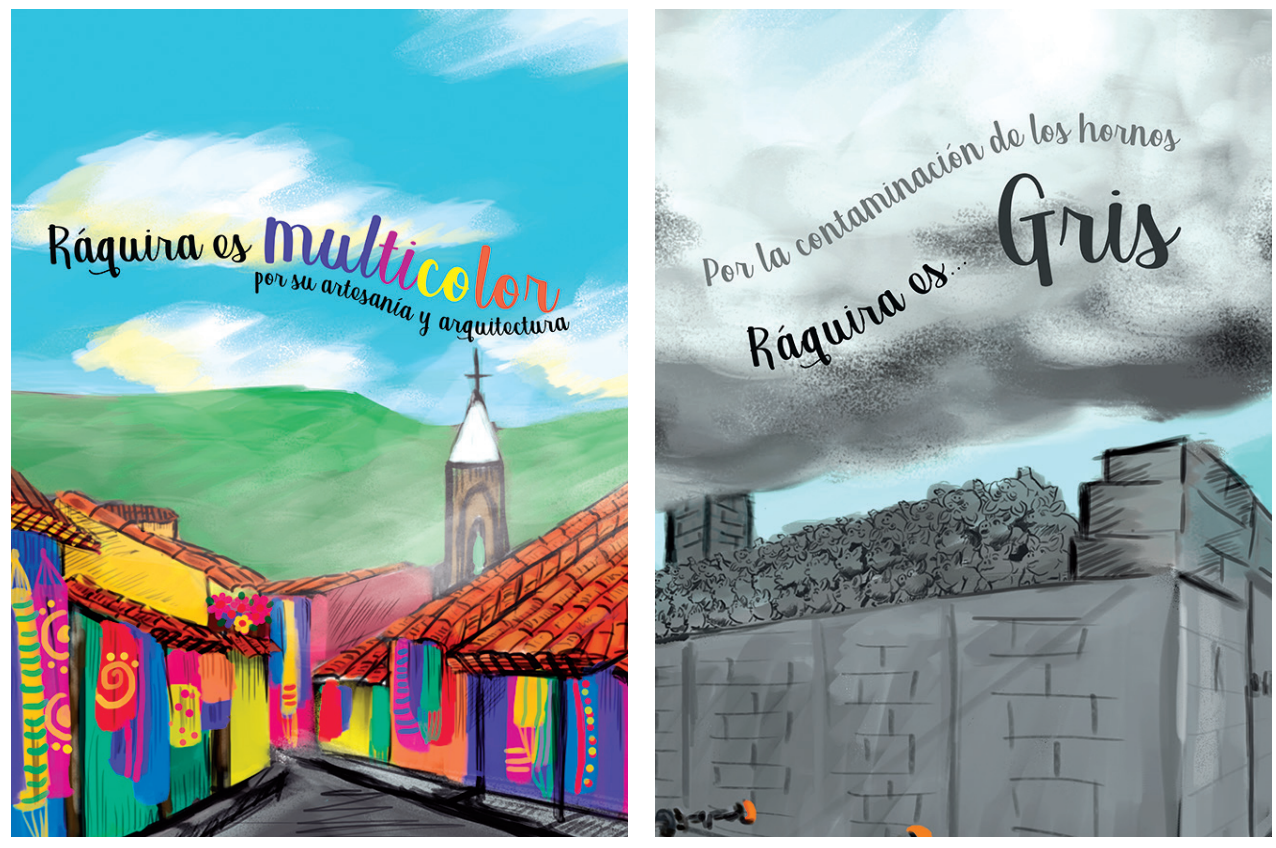

Figura 14. Cartel Arcilla.

Figura 15. Cartel Naranja.

Figura 16. Cartel Multicolor.

Figura 17. Cartel Violeta.

Figura 18. Cartel Gris. Fuente: diseño de Milena Vargas.

\section{CONCLUSIONES}

La percepción que lleva a los habitantes a identificar gamas cromáticas se encuentra estrechamente relacionada con varios factores: el tiempo de permanencia en Ráquira, las emociones y experiencias de vida particulares, las tradiciones locales reconocidas por cada quien y las condiciones contextuales. Por consiguiente, es preciso considerar que los resultados están sujetos al tiempo y al momento histórico de la realización del estudio. Un análisis similar aplicado posteriormente quizá arroje datos distintos. Además, debe tenerse presente la procedencia de gran parte de la información a partir de una muestra específica de estudiantes de secundaria, es decir, un grupo poblacional joven. 
En las asociaciones entre sitios representativos del municipio y diferentes colores se reconoce una relación emocional y afectiva de las personas con su entorno. Los resultados muestran que en los residentes se genera identidad desde el color hacia aspectos positivos, aunque también aparecen vinculaciones cromáticas indicativas de realidades negativas. Por su parte, los visitantes tienen percepciones favorables del lugar.

Amarillo, rojo, naranja y café se asocian con la arcilla, materia prima de la alfarería. Violeta y verde se relacionan con las flores y la vegetación. El azul expresa tranquilidad y se vincula con el cielo, la cascada y el río. En contraste, por medio del gris se plasma la contaminación del aire producida por los hornos usados en la cocción del material.

El color está ligado a la alfarería artesanal. De hecho, los resultados indican un patrón cromático con prevalencia de los tonos terracota y naranja que definen a este como un territorio de arcilla. Tal asociación corrobora la relevancia de la actividad: es la principal de tipo económico, genera apego emocional en la mayoría de pobladores, quienes se identifican con ella, es tradición, identidad y expresión cultural propia de Ráquira.

Se recomienda continuar el estudio en este municipio y analizar el color físico, dada la pertinencia de una comparación con los resultados de este otro componente del análisis. 


\section{REFERENCIAS BIBLIOGRÁFICAS}

Gobernación de Boyacá. (2012). Así es mi Boyacá. Tunja, Colombia: Boyacá 7 Días.

Lenclos, P. (1999). Colors of the world. París, Francia: W.W. Norton \& Company.

Peña, E. (09 de Diciembre de 1994). Ráquira, el pueblo más lindo de Boyacá. El Tiempo

Rodríguez, C. M. (2016). Sabores de la ciudad imaginada. Tunja, Colombia: Universidad de Boyacá.

Rodríguez, C. M. (2014a). ¿De qué color son las ciudades? Metodología de apreciación cromática urbana. Designia, 2(2), 14-35.

Rodríguez, C. M. (2014b). Percepciones e imaginarios del color urbano en Tunja. Kepes, 11(10), 49-65.

Rodríguez, C. M. (2013). Cromatología de la ciudad imaginada. Tunja, Colombia: Universidad de Boyacá.

Rodríguez, L. (2011). El Color de ciudad, una propuesta urbana. Arquitectura del Sur, (40), 70-81.

Silva, A. (2004). Bogotá imaginada. Bogotá, Colombia: Taurus.

Zúñiga, C. (2014). Bifurcaciones: un repertorio de apropiaciones espaciales de la zona centro de Tijuana. Recuperado de http://www.bifurcaciones.cl/2014/12/zuniga/ 